\title{
COMPARISON OF ON-LINE AND OFF-LINE FRIED PARAMETER ESTIMATION METHODS
}

\author{
O.A. Soloviev ${ }^{\mathrm{a}, \mathrm{b}}$, G.V. Vdovin ${ }^{\mathrm{a}, \mathrm{b}}$, V.V. Bezzubik ${ }^{\mathrm{b}}$ \\ ${ }^{a}$ Delft University of Technology, Delft, 2628 CD, The Netherlands \\ ${ }^{b}$ ITMO University, Saint Petersburg, 197101, Russian Federation \\ Corresponding author: bezzubik@mail.ru \\ Article info \\ Received 19.08.19, accepted 25.09.19 \\ Article in English \\ For citation: Soloviev O.A., Vdovin G.V., Bezzubik V.V. Comparison of on-line and off-line Fried parameter estimation methods. \\ Scientific and Technical Journal of Information Technologies, Mechanics and Optics, 2019, vol. 19, no. 6, pp. 959-965 (in English). \\ doi: 10.17586/2226-1494-2019-19-6-959-965
}

\section{Abstract}

We address the problem of high-accuracy estimation of the Fried parameter $r_{0}$ by comparing two approaches based on estimation of statistical properties of intensity-based wavefront measurements with parameter-fitting to the theoretically predicted values. In the first approach, the phase of the aberration-degraded field is restored from the measurements to obtain the statistical estimate for the structure function. Due to the iterative nature of the most phase retrieval methods, this approach requires significant computational time and thus cannot provide results in real time. In the second approach, the structure function of the sub-aperture wavefront slopes is directly calculated and related to the turbulence parameters in real time. We describe the equations used to obtain the estimate of the Fried parameter by both methods and check their accuracy with numerical simulations.

Keywords

wavefront aberrations, imaging through turbulence, Fried parameter, turbulence statistics

Acknowledgements

The research is carried out at ITMO University (grant 074-11-2018-004) under the financial support of the Ministry of Science and Higher Education of the Russian Federation.

The authors are very grateful to F. Inochkin for his assistance in preparing the manuscript for publication.

\section{СРАВНИТЕЛЬНЫЙ АНАЛИЗ МЕТОДОВ ОЦЕНКИ ПАРАМЕТРА ФРИДА}

\section{О.А. Соловьев ${ }^{\mathrm{a}, \mathrm{b}}$, Г.В. Вдовин ${ }^{\mathrm{a}, \mathrm{b}}$, В.В. Беззубик ${ }^{\mathrm{b}}$}

а Дельфтский Университет Технологий, Дельфт, 2628 CD, Нидерланды

b Университет ИТМО, Санкт-Петербург, 197101, Российская Федерация

Адрес для переписки: bezzubik@mail.ru

Информация о статье

Поступила в редакцию 19.08.19, принята к печати 25.09.19

Язык статьи - английский

Ссылка для цитирования: Соловьев О.А., Вдовин Г.В., Беззубик В.В. Сравнительный анализ методов оценки параметра Фрида // Научно-технический вестник информационных технологий, механики и оптики. 2019. Т. 19. № 6. С. 959-965. doi: 10.17586/2226-1494-2019-19-6-959-965

\section{Аннотация}

Проведено сравнение двух подходов к проблеме оценки величины параметра Фрида $r_{0}$, основанных на параметрической аппроксимации теоретических статистических свойств параметров волнового фронта значениями, полученными из датчика волнового фронта. В первом подходе структурная функция фазы вычисляется на основе восстановленного искаженного волнового фронта. Так как большинство методов восстановления фазы используют итерационные алгоритмы, данный подход требует значительных вычислительных затрат, что приводит к невозможности получения результатов в режиме реального времени. Во втором подходе структурная функция вычисляется непосредственно на основе значений локальных наклонов волнового фронта, что позволяет производить оценку величины $r_{0}$ в режиме реального времени. В работе получены выражения для расчета параметра Фрида $r_{0}$ для двух рассмотренных подходов, а также проведен сравнительный анализ полученных результатов.

\section{Ключевые слова}

аберрации волнового фронта, наблюдение в турбулентной атмосфере, параметр Фрида, статистика турбулентности

Благодарности

Работа выполнена в Университете ИТМО при финансовой поддержке Министерства науки и высшего образования Российской Федерации (грант 074-11-2018-004).

Авторы выражают благодарность Ф.М. Иночкину за помощь при подготовке публикации. 


\section{Introduction}

The Fried parameter [1], $r_{0}$, is a scaling coefficient describing the statistical properties of the wavefront degraded by turbulence described by the Kolmogorov's model. It is widely used in the adaptive optics and the turbulence strength is conveniently expressed as the ratio of the telescope diameter $D$ to the Fried parameter.

The quality of the image correction should be estimated against measured turbulence strength. Moreover, the parameters of the image restoration algorithm can be dynamically adjusted to match the optimal values for the momentary level of the turbulence. For this purpose, a hardware/software device for measuring of $r_{0}$ is required.

In literature, several methods of $r_{0}$ estimation are described. Most of them estimate the turbulence parameters through calculation of some statistical properties of the registered intensity values, like measured or calculated longexposure point spread function (PSF) [2], or of the restored wavefront, e.g. covariance of the estimated Zernike coefficients [3], structure functions of the phase differences [4], structure function of the sub-aperture wavefront slopes [5,6], or even from the control signals of a deformable mirror working in a closed loop [7]. The majority of them were used in off-line mode, that is, with turbulence parameters estimated and analyzed in a later time. In spite of that, they are based on direct, non-iterative calculations. They can be implemented as on-line methods with current advances in the computational speed and introduction of parallel computations based on GPU [8-10], and the measurements of $r_{0}$ could be provided in parallel with the wavefront measurements with a rate higher than speed of change of the turbulence parameters.

Lately, new algorithms have appeared, able to retrieve the phase either from the PSF or blurred image [1113] with increased accuracy, or from the Shack-Hartmann wavefront measurements with an accuracy higher that is achievable with standard slopes-integration methods $[14,15]$. This phase can be used for direct estimation of the wavefront statistics. Although the phase retrieval methods are iteration-based and thus are inherently slower than the mentioned above non-iterative methods, they can be used only off-line. However, due to a higher resolution and accuracy of the restored phase, they might be more accurate than the on-line methods.

The goal of this work is to compare the accuracy of $r_{0}$ estimation with on-line and off-line methods and select the best candidate to be implemented in the hardware.

\section{Methods of estimation of $r_{0}$}

All methods of $r_{0}$ estimation are based on the calculation of some statistical functions from the intensity measurements. According to the classification described above, we have chosen one method using direct, noniterative calculations based on the raw sensor data as representative of the on-line method (we have used the method of Silbaugh et al. [6]), and compared it with the results of direct calculation of the structure parameters on a restored phase, as would be restored by some of the off-line methods. Of course, the quality of the retrieved phase does depend on the chosen algorithm. For the sake of simplicity, we assumed here that both methods provide ideal noise-free measurements.

The method of $r_{0}$ estimation for both approaches are described below.

Off-line mode. In the off-line mode, the phase retrieved from the raw camera data is used for estimation of the statistical phase structure function.

In our simulations we have used the definition of the phase structure function according to [16] as variance of the phase differences:

$$
D_{\varphi}(\boldsymbol{\xi}, \boldsymbol{\rho})=\left\langle|\varphi(\xi)-\varphi(\xi+\boldsymbol{\rho})|^{2}\right\rangle
$$

where angle brackets denote the ensemble average.

For phase being stationary in wide-sense, the value of the structure function should not depend on the point $\xi$ of measurements. It gives the possibility (see [17] for details) to relate the phase structure function to the phase autocorrelation function $\Gamma_{\varphi}(\boldsymbol{\rho})$ as:

$$
D_{\varphi}(\boldsymbol{\rho})=2 \Gamma_{\varphi}(0)-2 \Gamma \varphi(\boldsymbol{\rho})
$$

By definition, the autocorrelation function involves integration over all domain of the phase, while in practice the data are available only in its "windowed" form. It prevents from using formula (1) directly, and it should be modified as follows.

Let phase data be available in some region $A$, with its characteristic function $P_{A}(\xi)$, so one has only part $\psi$ of the phase screen $\varphi$ :

$$
\psi(\xi)=\varphi(\xi) P_{\mathrm{A}}(\xi)
$$

Then, if $\varphi$ is stationary, the values of its structure function $D_{\varphi}$ should be equal for all point $\xi \in A$ such that $\xi+\boldsymbol{\rho} \in A$, and thus the integral over all these points should be equal to $D_{\varphi}(\boldsymbol{\rho}) S_{\boldsymbol{\rho}}$, where $S_{\boldsymbol{\rho}}$ is the area of the area $A_{\boldsymbol{\rho}}$ :

$$
D \varphi(\boldsymbol{\rho}) S_{\boldsymbol{\rho}}=\int_{\xi \in A \boldsymbol{\rho}} D(\xi, \boldsymbol{\rho}) \mathrm{d} \xi=\left\langle\int_{\xi \in A \boldsymbol{\rho}}|\varphi(\xi)-\varphi(\xi+\boldsymbol{\rho})|^{2} \mathrm{~d} \xi\right\rangle=\left\langle\int_{\xi \in A \boldsymbol{\rho}} \varphi(\xi)^{2}+\varphi(\xi+\boldsymbol{\rho})^{2}-2 \varphi(\xi)^{2} \varphi(\xi+\boldsymbol{\rho}) \mathrm{d} \xi\right\rangle .
$$


As condition $\xi \in A_{\boldsymbol{\rho}}$ is equivalent to $P_{A}(\xi) P_{A}(\xi+\boldsymbol{\rho})=1$, one can rewrite the last integral via cross-correlation functions Eq. (3):

$$
\int\left(\psi^{2}(\xi) P_{\mathrm{A}}(\boldsymbol{\xi}+\boldsymbol{\rho})+\psi^{2}(\xi+\boldsymbol{\rho}) P_{\mathrm{A}}(\xi) \varphi(\xi+\boldsymbol{\rho})\right) \mathrm{d} \xi=\Gamma_{\psi^{2}, P_{A}}(\boldsymbol{\rho})+\Gamma_{P_{A}, \psi} 2(\boldsymbol{\rho})-2 \Gamma_{\psi}(\boldsymbol{\rho}),
$$

where $\Gamma_{f, g}$ denotes the cross-correlation of $f$ and $g$.

Noting that $S_{\boldsymbol{\rho}}=\Gamma_{P_{A}}(\boldsymbol{\rho})$, the phase structure function can be expressed as:

$$
D_{\varphi}(\boldsymbol{\rho})=\left\langle\frac{\Gamma_{\psi^{2}, P_{A}}(\boldsymbol{\rho})+\Gamma_{P_{A}, \psi^{2}}(\boldsymbol{\rho})-2 \Gamma_{\psi}(\boldsymbol{\rho})}{\Gamma_{P_{A}}(\boldsymbol{\rho})}\right\rangle,
$$

where all cross-correlations involve only functions with a finite support, and thus can be easily calculated using (discrete) Fourier transform.

Knowing the theoretical formula for the phase structure function for the Kolmogorov spectrum:

$$
D_{\varphi}(\boldsymbol{\rho})=6.68\left(\frac{\boldsymbol{\rho}}{r_{0}}\right)^{5 / 3}
$$

and having computed the numerical phase structure function applying Eq. (4), one can use one parameter fitting to estimate $r_{0}$.

On-line mode. In on-line mode, the Fried parameter is estimated from the slope structure function, using method of reference [6]. Here, the same formula (4) of the structure function calculation can be used with the phase values replaced by the averaged over sub-apertures gradients of the phase. It decreases the amount of calculations dramatically, so they can be performed for every $N^{\text {th }}$ frame, say, in parallel with the measurements.

The Fried parameter can be again evaluated from the parameter fitting of the ensemble averaged slope structure function to the theoretical value given by [6]:

$$
\begin{aligned}
D_{S}^{\hat{x}}\left(\Delta x_{s}, \Delta y_{s}, \Delta x_{t}, \Delta y_{t}\right)=\gamma_{\beta} d^{-2}\left(\frac{d}{r_{0}}\right)^{\beta-2} \int_{0}^{\infty} d u \int_{0}^{\infty} d z w(z) \operatorname{tri}(u) \\
\times \\
\quad\left\{\left[2\left|\Delta x_{s}+\Delta x_{t}(z), u+\Delta y_{s}+\Delta y_{t}(z)\right|^{\beta-2}\right.\right. \\
-\left|\Delta x_{s}+\Delta x_{t}(z)-1, u+\Delta y_{s}+\Delta y_{t}(z)\right|^{\beta-2} \\
\left.-\left|\Delta x_{s}+\Delta x_{t}(z)+1, u+\Delta y_{s}+\Delta y_{t}(z)\right|^{\beta-2}\right] \\
\left.-2\left(|0, u|^{\beta-2}-|1, u|^{\beta-2}\right)\right\},
\end{aligned}
$$

where $d$ is a spatial separation between slopes measurements, $\beta$ and $\gamma_{\beta}$ are the turbulence power law constants, $\operatorname{tri}(u)$ is a triangle function, $w(z)$ is a relative weight of turbulence layer at distance $z$, and $\Delta x_{s}, \Delta y_{s}, \Delta x_{t}(z)$, and $\Delta y_{t}(z)$ are normalized spatial and temporal separation of the slopes:

$$
\begin{aligned}
& \Delta x_{s}=\left(x-x^{\prime}\right) / d, \\
& \Delta y_{s}=\left(y-y^{\prime}\right) / d, \\
& \Delta x_{t}(z)=v_{x}(z)\left(t-t^{\prime}\right) / d, \\
& \Delta y_{t}(z)=v_{y}(z)\left(t-t^{\prime}\right) / d,
\end{aligned}
$$

with $\mathbf{v}=\left(v_{x}, v_{y}\right)$ being the wind speed.

In practice, to speed up the calculation even further, the slope structure function is calculated only in one spatial direction for the measurement taken at the same time, so:

a) equation (5) is reduced to a simpler integral:

$$
\begin{aligned}
D_{S}^{\hat{x}} & \left(\Delta x_{S}, \Delta y_{s}, 0,0\right)=\gamma_{\beta} d^{-2}\left(\frac{d}{r_{0}}\right)^{\beta-2} \int d u \int_{0}^{\infty} d z w(z) \operatorname{tri}(u) \\
& \times\left[2\left|\Delta x_{S}, u+\Delta y_{S}\right|^{\beta-2}\right. \\
& -\left|\Delta x_{S}-1, u+\Delta y_{S}\right|^{\beta-2} \\
& \left.-\left|\Delta x_{S}+1, u+\Delta y_{S}\right|^{\beta-2}\right] \\
& \left.-2\left(|0, u|^{\beta-2}-|1, u|^{\beta-2}\right)\right\}
\end{aligned}
$$

which can be evaluated numerically for the given parameter and stored for further use;

b) makes it possible to calculate the slope function directly by definition, without using Fourier transform. 


\section{Numerical experiments}

For the numerical experiments, simulated turbulent phase screens were used. To exclude the dependence of the results on the phase screen simulation quality, two series of numerical experiments, with different turbulence simulators, were performed.

In the first numerical series, 500 random phase screens of Kolmogorov statistics were simulated by method of [18] realized by the authors in MATLAB for 25 different values of $D / r_{0}=25 / i, i=1, \ldots, 25$; that is 20 realizations for each fixed of $r_{0}$ (we refer to the set of screens corresponding to one fixed set of parameters as experiment). The size of each screen was either a) $128 \times 128$ pixels or b) $1024 \times 1024$ to simulate a low- and high-resolution retrieved phase. This approach is in fact dimensionless (only ratio $D / r_{0}$ is known); it generates mutually uncorrelated phase screens.

In the second series, the phase screens generated by OOMAO toolbox [19] were used. In this series, the resolution was set to $172 \times 172$ pixels, $D$ was set to $1 \mathrm{~m}$, and $r_{0}$ was set to a) $1, \ldots, 10 \mathrm{~cm}$, and b) $15,30,45,60,75$ $\mathrm{cm}$, with 100 frames in each experiment.

OOMAO simulates phase resulted from a wind-driven turbulence layer, which corresponds to the expected situation in practical measurements. To obtain less correlated phase screens, the wind speed was set to $100 \mathrm{~m} / \mathrm{s}$, which corresponded to $6.66 \mathrm{~m} /$ frame with simulated frame rate of $15 \mathrm{fps}$. In practice, one would need either to estimate the wind speed and include in calculations also temporal separations between slopes using the complete formula given by equation (5), or increase the time delay between the frames used for the turbulence estimation.

In both series, the procedure was as follows: for each of the turbulent screens, the structure function was calculated according to formula (4), and the result was averaged over experiment.

In addition, the subaperture slopes were calculated by averaging the phase gradient values, and the slope structure function was calculated for every slope measurement simulation with later averaging over experiment.

Phase structure functions and slope structure function were plotted for each of the experiments and compared with the theoretical plots.

Finally, the Fried parameter was estimated by parameter fitting of the obtained structure functions or their cross-sections in $x$ - and $y$-directions to the theoretical curve, and the values estimated by both methods were compared with the values used for phase screen simulations (ground truth).

\section{Results and discussion}

Fig. 1 shows phase structure functions obtained from the first series for two different resolutions. Fig. 2 shows $x$ - and $y$-cross-sections of plots of Fig. 1 in log-log plot, against a straight line of 5/3 slope.
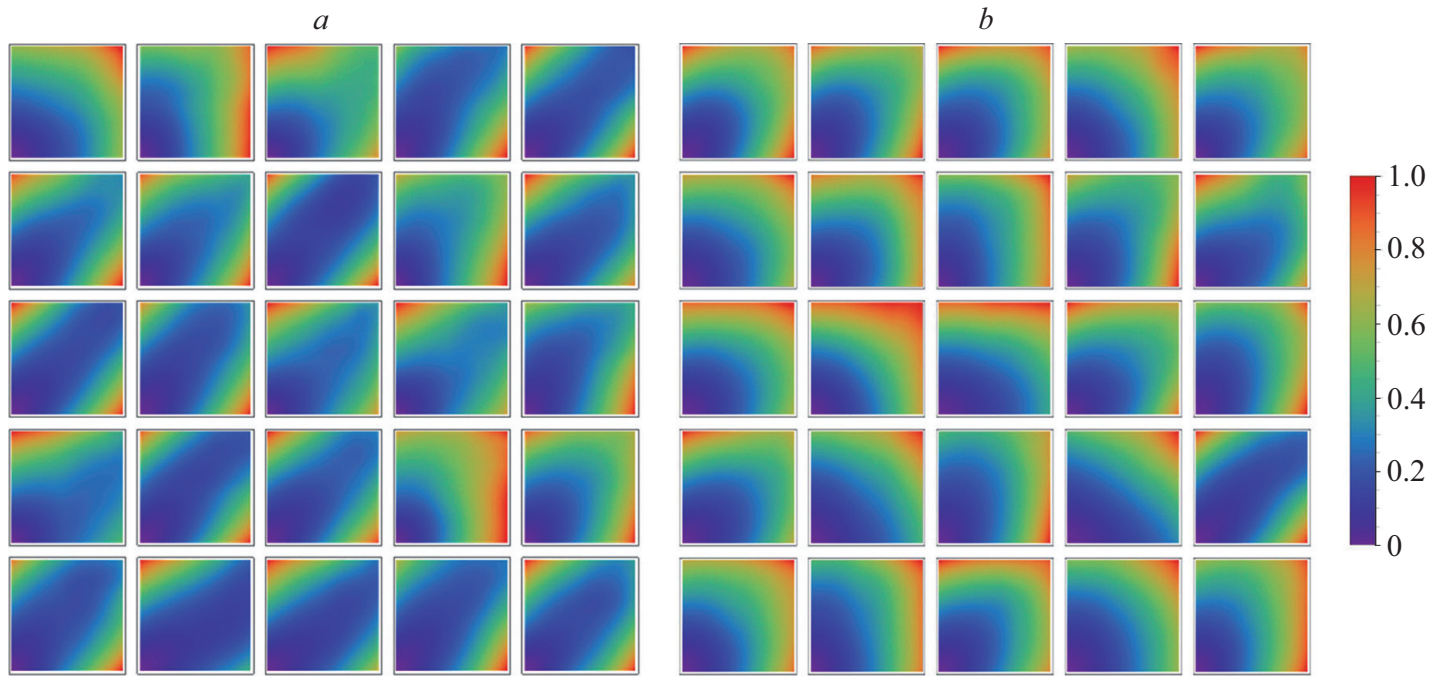

Fig. 1. Phase structure functions $D_{\varphi}(\boldsymbol{\rho})$ obtained for the phase screens of resolution $128 \times 128(a)$ and $1024 \times 1024$ pixels (b), shown in normalized color scales for $r_{0}=D / 25,2 D / 25, \ldots D$, left to right, top to bottom. The structure function is shown for non-negative components $x, y$ of $\rho=(x, y)$

One can note that the plots of Fig. 1 are not isotropic for lower resolution and that the slopes of the crosssections of Fig. 2 obey the 5/3 rule in the middle part only. Both facts can be attributed to: a) errors of the simulation algorithms and b) non-uniform averaging, as can be seen from Eq. (2): for a smaller separations $\boldsymbol{\rho}$, one can obtain larger ensemble of squared phase differences to average.

Structure functions calculated for the second series (see Fig. 3) demonstrated more isotropic character.

Fig. 4 shows the results of $r_{0}$ estimation for series 1 and 2 with on-line and off-line methods. Quite unexpectedly, the estimation obtained with off-line methods is less accurate for series 1, and is better estimated by slope structure function. It can be explained as follows: due to the calculation via averaged over sub-aperture wavefront gradients, the on-line methods use implicitly additional data smoothing and provide a more robust result. 


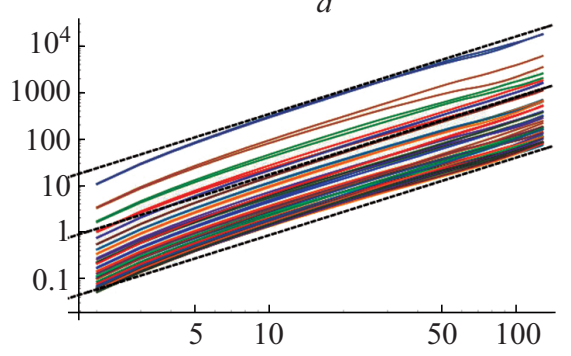

$b$

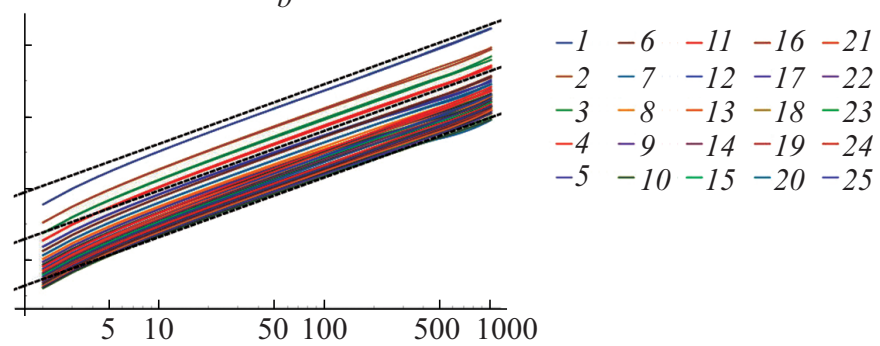

Fig. 2. $x$ and $y$ - cross-sections of statistical structure functions obtained for the phase screens of resolution $128 \times 128(a)$ and $1024 \times 1024$ pixels $(b)$
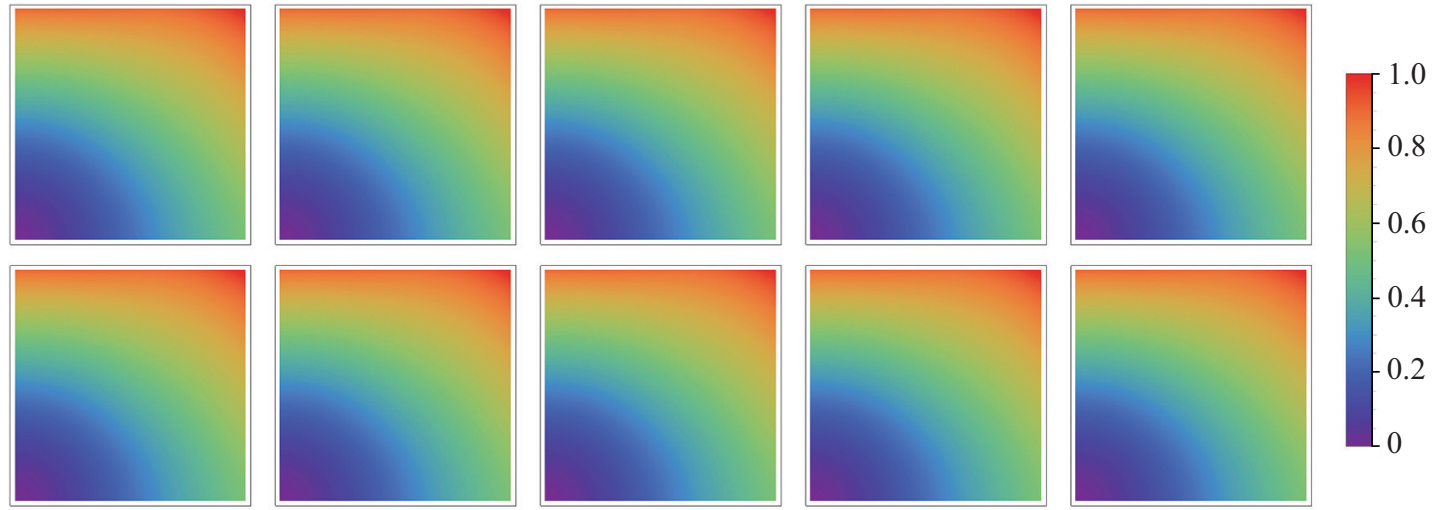

Fig. 3. Normalized phase structure functions obtained from series 2
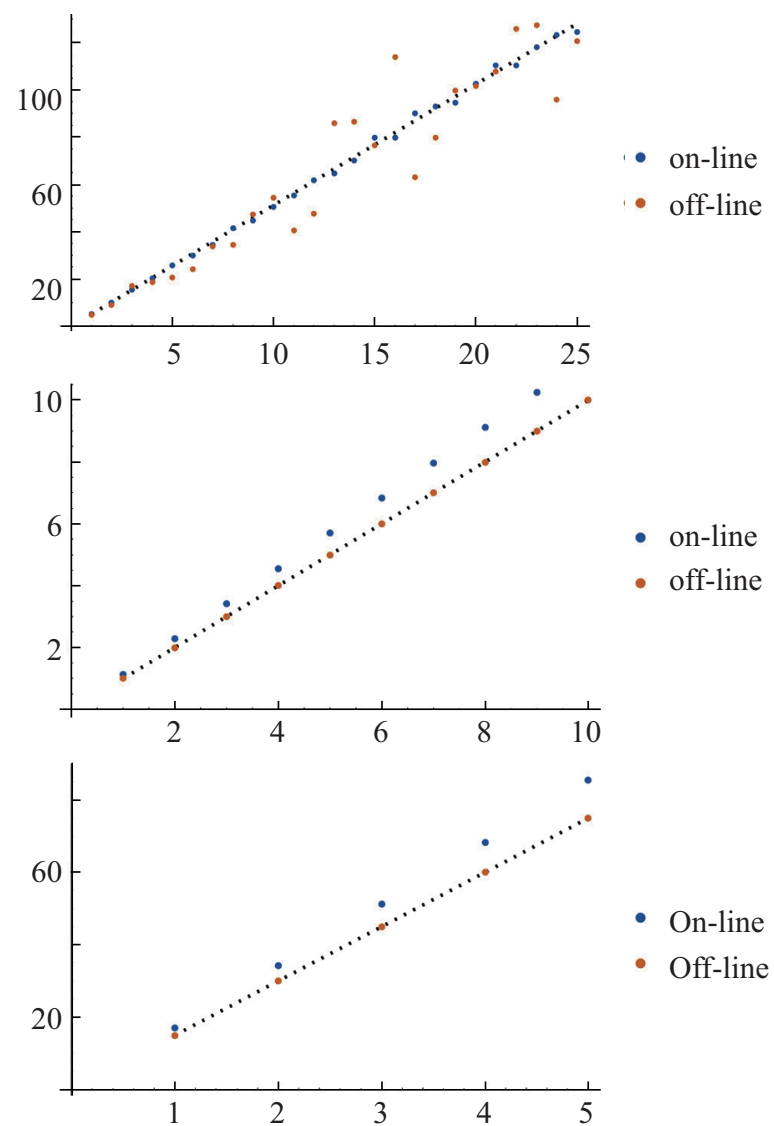

Fig. 4. Estimation of $r_{0}$ obtained with on-line and off-line methods for series 1 (top), and two cases of series $2 \mathrm{a}$ (middle) and $2 \mathrm{~b}$ (bottom). In all plots, horizontal axis is the number of experiment in the series, vertical axis is $r_{0}$ value converted to image pixels. The dotted line shows the ground truth 
Results obtained with the series 2 demonstrate excellent $r_{0}$ restoration with the offline methods, while the on-line methods show some fixed scaling error. The latter can be attributed to the remaining correlation between the phase screens.

\section{Conclusion}

We have implemented and tested two methods of the Fried parameter $r_{0}$ estimation in numerical simulations. While the slow off-line methods, based on wavefront reconstruction, provide a more accurate results, these methods require more uncorrelated measurements and have higher computational complexity. For practical real-time application the estimate of $r_{0}$ is used as a tuning parameter for image improving algorithms, therefore, the method based on the real-time calculation of structure function of the wavefront derivatives have clear advantage both in the ease of implementation and in the calculation complexity.

\section{Литература}

1. Roggemann M.C., Welsh B. Imaging through turbulence. CRC Press, 1996. 320 p.

2. Weiss A.R., Hippler S., Kasper M.E., Wooder N.J., Quartel J.C. Simultaneous Measurements of the Fried Parameter $r(0)$ and the Isoplanatic Angle theta(0) using SCIDAR and Adaptive Optics - First Results // Astronomical society of the pacific conference series. 2002. V. 266. P. 86-95.

3. Andrade P.P., Garcia P.J.V., Correia C.M., Kolb J., Carvalho M.I. Estimation of atmospheric turbulence parameters from ShackHartmann wavefront sensor measurements // Monthly Notices of the Royal Astronomical Society. 2019. V. 483. P. 1192-1201. doi: $10.1093 / \mathrm{mnras} / \mathrm{sty} 3181$

4. Sergeyev A.V., Roggemann M.C. Monitoring the statistics of turbulence: Fried parameter estimation from the wavefront sensor measurements // Applied Optics. 2011. V. 50. N 20. P. 35193528. doi: 10.1364/AO.50.003519

5. Dayton D., Pierson B., Spielbusch B., Gonglewski J. Atmospheric structure function measurements with a Shack-Hartmann wavefront sensor // Optics Letters. 1991. V. 17. N 24. P. 1737-1739. doi: 10.1364/OL.17.001737

6. Silbaugh E.E., Welsh B.M., Roggemann M.C. Characterization of atmospheric turbulence phase statistics using wave-front slope measurements // Journal of the Optical Society of America A: Optics and Image Science, and Vision. 1996. V. 13. N 12. P. 2453-2460. doi: 10.1364/JOSAA.13.002453

7. Jolissaint L., Ragland S., Christou J., Wizinowich P. Determination of the optical turbulence parameters from the adaptive optics telemetry: critical analysis and on-sky validation // Applied Optics. 2018. V. 57. N 27. P. 7837-7856. doi: 10.1364/AO.57.007837

8. Wang C., Dun X., Fu Q., Heidrich W. Ultra-high resolution coded wavefront sensor // Optics Express. 2017. V. 25. N 12. P. 13736-13746. doi: 10.1364/OE.25.013736

9. Mompeán J., Aragón J.L., Prieto P.M., Artal P. GPU-based processing of Hartmann-Shack images for accurate and high-speed ocular wavefront sensing // Future Generation Computer Systems. 2019. V. 91. P. 177-190. doi: 10.1016/j.future.2018.09.010

10. Wu Y., Sharma M.K., Veeraraghavan A. WISH: wavefront imaging sensor with high resolution // Light: Science and Applications. 2019. V. 8. N 1. P. 44. doi: 10.1038/s41377-019-0154-x

11. Shechtman Y., Eldar Y.C., Cohen O., Chapman H.N., Miao J., Segev M. Phase Retrieval with Application to Optical Imaging: A contemporary overview // IEEE Signal Processing Magazine. 2015. V. 32. N 3. P. 87-109. doi: 10.1109/MSP.2014.2352673

12. Lu J.-T., Lu C.-H., Fleischer J.W. Enhanced phase retrieval using nonlinear dynamics // Optics Express. 2016. V. 24. N 22. P. 25091-25102. doi: 10.1364/OE.24.025091

13. Piscaer P.J., Gupta A., Soloviev O., Verhaegen M. Modalbased phase retrieval using Gaussian radial basis functions // Journal of the Optical Society of America A: Optics and Image Science, and Vision. 2018. V. 35. N 7. P. 1233-1242. doi: 10.1364/JOSAA.35.001233

14. Polo A., Kutchoukov V., Bociort F., Pereira S., Urbach H.P. Determination of wavefront structure for a Hartmann Wavefront Sensor using a phase-retrieval method // Optics Express. 2012. V. 20. N 7. P. 7822-7832. doi: 10.1364/OE.20.007822

\section{References}

1. Roggemann M.C., Welsh B. Imaging through turbulence. CRC Press, 1996, 320 p.

2. Weiss A.R., Hippler S., Kasper M.E., Wooder N.J., Quartel J.C. Simultaneous Measurements of the Fried Parameter $\mathrm{r}(0)$ and the Isoplanatic Angle theta(0) using SCIDAR and Adaptive Optics First Results. Astronomical society of the pacific conference series, 2002, vol. 266, pp. 86-95.

3. Andrade P.P., Garcia P.J.V., Correia C.M., Kolb J., Carvalho M.I. Estimation of atmospheric turbulence parameters from ShackHartmann wavefront sensor measurements. Monthly Notices of the Royal Astronomical Society, 2019, vol. 483, pp. 1192-1201. doi: $10.1093 / \mathrm{mnras} / \mathrm{sty} 3181$

4. Sergeyev A.V., Roggemann M.C. Monitoring the statistics of turbulence: Fried parameter estimation from the wavefront sensor measurements. Applied Optics, 2011, vol. 50, no. 20, pp. 35193528. doi: 10.1364/AO.50.003519

5. Dayton D., Pierson B., Spielbusch B., Gonglewski J. Atmospheric structure function measurements with a Shack-Hartmann wavefront sensor. Optics Letters, 1991, vol. 17, no. 24, pp. 1737-1739. doi: 10.1364/OL.17.001737

6. Silbaugh E.E., Welsh B.M., Roggemann M.C. Characterization of atmospheric turbulence phase statistics using wave-front slope measurements. Journal of the Optical Society of America A: Optics and Image Science, and Vision, 1996, vol. 13, no. 12, pp. 2453-2460. doi: 10.1364/JOSAA.13.002453

7. Jolissaint L., Ragland S., Christou J., Wizinowich P. Determination of the optical turbulence parameters from the adaptive optics telemetry: critical analysis and on-sky validation. Applied Optics, 2018, vol. 57, no. 27, pp. 7837-7856. doi: 10.1364/AO.57.007837

8. Wang C., Dun X., Fu Q., Heidrich W. Ultra-high resolution coded wavefront sensor. Optics Express, 2017, vol. 25, no. 12, pp. 13736-13746. doi: 10.1364/OE.25.013736

9. Mompeán J., Aragón J.L., Prieto P.M., Artal P. GPU-based processing of Hartmann-Shack images for accurate and high-speed ocular wavefront sensing. Future Generation Computer Systems, 2019, vol. 91, pp. 177-190. doi: 10.1016/j.future.2018.09.010

10. Wu Y., Sharma M.K., Veeraraghavan A. WISH: wavefront imaging sensor with high resolution. Light: Science and Applications, 2019, vol. 8, no. 1, pp. 44. doi: 10.1038/s41377-019-0154-X

11. Shechtman Y., Eldar Y.C., Cohen O., Chapman H.N., Miao J., Segev M. Phase Retrieval with Application to Optical Imaging: A contemporary overview. IEEE Signal Processing Magazine, 2015, vol. 32, no. 3, pp. 87-109. doi: 10.1109/MSP.2014.2352673

12. Lu J.-T., Lu C.-H., Fleischer J.W. Enhanced phase retrieval using nonlinear dynamics. Optics Express, 2016, vol. 24, no. 22, pp. 25091-25102. doi: 10.1364/OE.24.025091

13. Piscaer P.J., Gupta A., Soloviev O., Verhaegen M. Modal-based phase retrieval using Gaussian radial basis functions. Journal of the Optical Society of America A: Optics and Image Science, and Vision, 2018, vol. 35, no. 7, pp. 1233-1242. doi: 10.1364/JOSAA.35.001233

14. Polo A., Kutchoukov V., Bociort F., Pereira S., Urbach H.P. Determination of wavefront structure for a Hartmann Wavefront Sensor using a phase-retrieval method. Optics Express, 2012, vol. 20, no. 7, pp. 7822-7832. doi: 10.1364/OE.20.007822 
15. Li J., Gong Y., Chen H., Hu X. Wave-front reconstruction with Hartmann-Shack sensor using a phase-retrieval method // Optics Communications. 2015. V. 336. P. 127-133. doi: 10.1016/j.optcom.2014.09.086

16. Adaptive Optics in Astronomy / Ed. by F. Roddier. Cambridge University Press, 1999. 411 p.

17. Goodman J.W. Statistical Optics. New York: A WileyInterscience publication, 1985.

18. Lane R.G., Glindemann A., Dainty J.C. Simulation of a Kolmogorov phase screen // Waves in Random Media. 1992. V. 2. N 3. P. 209-224. doi: 10.1088/0959-7174/2/3/003

19. Conan R., Correia C. Object-oriented Matlab adaptive optics toolbox. // Proceedings of SPIE. 2014. V. 9148. P. 91486C. doi: $10.1117 / 12.2054470$

\section{Authors}

Oleg A. Soloviev - PhD, Senior Research Fellow, Delft University of Technology, Delft, 2628 CD, The Netherlands; Professor-researcher, ITMO University, Saint Petersburg, 197101 Russian Federation, Scopus ID: 9639841800, ORCID ID: 0000-0003-3761-9192,oleg.soloviev@gmail.com

Gleb V. Vdovin - PhD, Professor, Delft University of Technology, Delft, 2628 CD, The Netherlands; Professor-researcher, ITMO University, Saint Petersburg, 197101, Russian Federation, Scopus ID: 35569820200, ORCID ID: 0000-0001-9716-1043, g.v.vdovine@tudelft.nl

Vitalii V. Bezzubik - Leading Engineer, ITMO University, Saint Petersburg, 197101, Russian Federation, Scopus ID: 6602820139 ORCID ID: 0000-0002-3418-0957, bezzubik@mail.ru
15. Li J., Gong Y., Chen H., Hu X. Wave-front reconstruction with Hartmann-Shack sensor using a phase-retrieval method. Optics Communications, 2015, vol. 336, pp. 127-133. doi: 10.1016/j.optcom.2014.09.086

16. Adaptive Optics in Astronomy / Ed. by F. Roddier. Cambridge University Press, 1999, $411 \mathrm{p}$

17. Goodman J.W. Statistical Optics. New York, A WileyInterscience publication, 1985.

18. Lane R.G., Glindemann A., Dainty J.C. Simulation of a Kolmogorov phase screen. Waves in Random Media, 1992, vol. 2, no. 3, pp. 209-224. doi: 10.1088/0959-7174/2/3/003

19. Conan R., Correia C. Object-oriented Matlab adaptive optics toolbox. Proceedings of SPIE, 2014, vol. 9148, pp. 91486C. doi: $10.1117 / 12.2054470$

\section{Авторы}

Соловьёв Олег Александрович - PhD, старший научный сотрудник, Дельфтский Университет Технологий, Дельфт, 2628 CD, Нидерланды; профессор-исследователь, Университет ИТМО, Санкт-Петербург, 197101, Российская Федерация, Scopus ID: 9639841800, ORCID ID: 0000-0003-3761-9192, oleg.soloviev@gmail.com

Вдовин Глеб Валерьевич - PhD, профессор, Дельфтский Университет Технологий, Дельфт, 2628 CD, Нидерланды; профессор-исследователь, Университет ИТМО, Санкт-Петербург, 197101, Российская Федерация, Scopus ID: 35569820200, ORCID ID: 0000-0001-9716-1043,g.v.vdovine@tudelft.nl

Беззубик Виталий Вениаминович - ведущий инженер, Университет ИТМО, Санкт-Петербург, 197101, Российская Федерация, Scopus ID: 6602820139, ORCID ID: 0000-0002-3418-0957, bezzubik@mail.ru 